\title{
Prevalence of Schistosoma japonicum infection in water buffaloes in selected areas in Davao del Norte and Davao de Oro, the Philippines
}

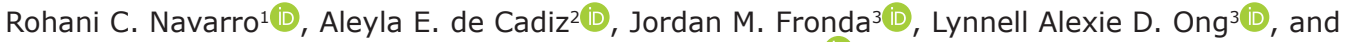 \\ Vicente Y. Belizario Jr. ${ }^{3,4}$ (id
}

\begin{abstract}
1. National Institute of Molecular Biology and Biotechnology, National Institutes of Health, University of the Philippines Manila, Manila, Philippines; 2. Department of Biological Sciences and Environmental Studies, College of Science and Mathematics, University of the Philippines Mindanao, Davao City, Philippines; 3. Neglected Tropical Diseases Study Group, National Institutes of Health, University of the Philippines Manila, Manila, Philippines; 4. Department of Parasitology, College of Public Health, University of the Philippines Manila, Manila, Philippines. Corresponding author: Rohani C. Navarro, e-mail: rbcena@up.edu.ph Co-authors: AED: aedecadiz@up.edu.ph, JMF: fronda.jordan@gmail.com, LADO: Idong@up.edu.ph, VYB: vybelizario@up.edu.ph

Received: 01-10-2020, Accepted: 15-01-2021, Published online: 16-02-2021
\end{abstract}

doi: www.doi.org/10.14202/IJOH.2021.12-18 How to cite this article: Navarro RC, de Cadiz AE, Fronda JM, Ong LAD, Belizario Jr VY (2021) Prevalence of Schistosoma japonicum infection in water buffaloes in selected areas in Davao del Norte and Davao de Oro, the Philippines, Int. J. One Health, 7(1): 12-18.

\begin{abstract}
Background and Aim: Schistosomiasis ( $\mathrm{SCH}$ ) japonica is a zoonotic disease that can infect several mammalian hosts. Bovines, particularly water buffaloes, are considered the most important reservoir hosts due to the high levels of schistosome eggs, they excrete into the environment. In the Philippines, the previous studies have revealed a high prevalence of SCH in bovines in selected provinces in Luzon, Visayas, and Mindanao. However, there is a lack of studies on SCH in the Davao Region, Mindanao, where the infection remains a public health concern. This study aimed to determine the prevalence of $\mathrm{SCH}$ in water buffaloes in four barangays (villages) each in Braulio Dujali, Davao del Norte and Maragusan, Davao de Oro, Southeastern Mindanao, the Philippines.
\end{abstract}

Materials and Methods: Fecal samples from 91 water buffaloes were collected intrarectally, processed using the formalinethyl acetate sedimentation technique, and examined microscopically to determine the prevalence of SCH.

Results: A total of three water buffaloes (8.6\%) in Maragusan were determined to be positive for Schistosoma japonicum, while none in Braulio Dujali. The prevalence of other parasites (Fasciola spp. [53.8\%], Paramphistome spp. [20.9\%], Amphistome spp. [16.5\%], Strongyle spp. [11.0\%], Balantidium spp. [9.9\%], Eurytrema spp. [2.2\%], and Gongylonema pulchrum [1.1\%]) was also observed.

Conclusion: The results of the study provide baseline data on the presence of S. japonicum in water buffaloes in the Davao Region, Mindanao. Strategies for controlling and eliminating SCH in animal reservoir hosts, especially in water buffaloes, are necessary for the long-term control and elimination of SCH in humans.

Keywords: formalin-ethyl acetate sedimentation technique, prevalence, Schistosoma japonicum, schistosomiasis, water buffalo.

\section{Introduction}

Schistosomiasis ( $\mathrm{SCH})$, which is caused by blood flukes from the Schistosoma genus, affects more than 230 million people worldwide [1]. It mostly affects poor and rural communities, mainly agricultural and fishing populations. Schistosoma japonicum is the causative agent of $\mathrm{SCH}$ in China, Indonesia, and the Philippines [2]. In the Philippines, $\mathrm{SCH}$ is endemic in 28 provinces across 12 regions, with approximately 12 million people at risk and 2.5 million directly exposed to it [3].

Unlike other schistosome species, $\mathrm{SCH}$ japonica is a zoonotic disease that can infect several mammalian

Copyright: Navarro, et al. This article is an open access article distributed under the terms of the Creative Commons Attribution 4.0 International License (http://creativecommons.org/licenses/ by/4.0/), which permits unrestricted use, distribution, and reproduction in any medium, provided you give appropriate credit to the original author(s) and the source, provide a link to the Creative Commons license, and indicate if changes were made. The Creative Commons Public Domain Dedication waiver (http:// creativecommons.org/ publicdomain/zero/1.0/) applies to the data made available in this article, unless otherwise stated. hosts, including cattle, water buffaloes, pigs, horses, goats, dogs, cats, rats, and monkeys [4-6], making it difficult to control the infection [6]. Bovines, particularly water buffaloes, are considered the most important reservoir hosts due to the high levels of schistosome eggs they excrete into the environment $[7,8]$. A study in China has shown that environmental contamination attributable to 238 infected bovines was approximately 28.7 million eggs per day [8].

Humans become infected with SCH when the larval forms of the parasite, released by the intermediate snail host Oncomelania hupensis quadrasi, penetrate the skin during contact with infested water. Provision of veterinary public health activities (which are defined as activities conducted at the human-animal interface that required to prevent, control, and eliminate suffering and economic loss caused by neglected zoonotic diseases such as $\mathrm{SCH}$ ) is included in the recommended integrated approach by the World Health Organization to overcome the global impact of parasitic neglected tropical diseases [9]. 
In the Philippines, recent studies on the prevalence of $\mathrm{SCH}$ in bovines were documented. In the Cagayan Province, 26\% and $46 \%$ prevalence in water buffaloes were determined using enzyme-linked immunosorbent assay and polymerase chain reaction (PCR), respectively [10]. In the Leyte Province, high prevalence at $51.5 \%$ in water buffaloes was observed by the quantitative PCR (qPCR) technique [11]. Prevalence in bovines in the North Samar Province was also high at $62.09 \%$ and $81.07 \%$, as determined using the formalin-ethyl acetate sedimentation (FEA-SD) and qPCR techniques, respectively [12]. A recent study in South Cotabato has shown that $48.6 \%$ of cattle and $60.5 \%$ of water buffaloes are positive for the infection as determined using the FEA-SD technique [13]. However, there are no studies documenting the presence of $\mathrm{SCH}$ in water buffaloes in the Davao Region, Mindanao, where $\mathrm{SCH}$ remains a public health concern.

Hence, this study aimed to determine the prevalence of SCH in water buffaloes in selected barangays (villages) in two provinces in Southeastern Mindanao, the Philippines.

\section{Materials and Methods}

Ethical approval

All animal handling procedures were approved by the Institutional Animal Care and Use Committee at the University of the Philippines (UP) Manila (UPM IACUC 2019-025). The study protocol was also approved by the UP Manila Research Ethics Board (UPMREB 2019-326-01). Informed consent was obtained from the owners before the collection of fecal samples, and confidentiality of data and privacy of water buffalo's owners were safeguarded.

\section{Study site, period, and sampling procedure}

The municipalities of Braulio Dujali in Davao del Norte (DDN) and Maragusan in Davao de Oro (DDO), Southeastern Mindanao, the Philippines, were chosen as the study areas (Figure-1). Map was created using Free and Open Source QGIS software version 3.1.6. DDN comprises eight municipalities, three cities, and 223 barangays with a total population of 1,016,332, while DDO comprises 11 municipalities and 105 barangays, with a total population of 316,342 [14]. The main source of livelihood in both provinces is farming. A total of four barangays each in Braulio Dujali (Cabayangan, Magupising, New Casay, and Poblacion) and Maragusan (Lahi, Pamintaran, Tigbao, and Tupaz) were selected due to their known endemicity of SCH. The samples were collected in September 2019. The cross-sectional study utilized purposive sampling, wherein apparently healthy male and female water buffaloes in the $\mathrm{SCH}$-endemic barangays were included in the study. Animals in the study site were normally seen tied to a tree and allowed to wallow in mudhole or irrigation canals during daytime and kept in a rural pen at night.

\section{Stool collection, processing, and examination}

Fecal samples from 91 water buffaloes, aged between 7 months and 25 years old, were collected intrarectally by a team of veterinarians and animal technicians. Fecal samples (50 $\mathrm{g}$ for each animal) were weighed, labeled, and stored in a clean screw cap container with $10 \%$ formalin. The formalinized fecal samples were processed using the FEA-SD technique [15] and examined microscopically by three researchers. Two veterinary parasitologists validated observed parasites.

\section{Data processing and analysis}

Data were encoded using Microsoft Excel 2016, processed, and analyzed using Epi Info version 7.2. (CDC, Atlanta, Georgia, USA). A sample was considered positive for a parasite if at least one ova/parasite was found in the microscopic examination. The prevalence of each parasite was calculated by dividing the number of positive cases by the total number of examined water buffaloes and multiplied by 100 . To validate the identification, images of the parasites were examined by three microscopists and verified by two veterinary parasitologists from the Department of Veterinary Parasitology, College of Veterinary Medicine, University of the Philippines, Los Baños.

\section{Results}

A total of 91 water buffaloes, 56 from Braulio Dujali and 35 from Maragusan, were included in the study. A total of $3(8.6 \%)$ water buffaloes were determined to be positive for $S$. japonicum in Maragusan, while none in Braulio Dujali. Fasciola spp. was the most prevalent parasite $(53.8 \%)$ observed in the sampled water buffaloes, followed by Paramphistome spp. (20.9\%), Amphistome spp. (16.5\%), Strongyle spp. (11.0\%), Balantidium spp. (9.9\%), Eurytrema spp. (2.2\%), and Gongylonema pulchrum (1.1\%) (Table-1). In Maragusan, one case of Schistosoma spp. was observed in a cow (Figure-2b). Representative images of the identified parasites are shown in Figure-2a-i.

\section{Discussion}

This study investigated the presence of $S$. japonicum in water buffaloes in DDO, Southeastern Mindanao, the Philippines, using the FEA-SD technique. The overall prevalence (3.3\%) of S. japonicum observed at the study sites was considerably lower than that in the previous studies, which used the same technique in West Samar (93.2\%) [16], North Samar (62.1\%) [12], and South Cotabato (60.5\%) [13]. This discrepancy may be attributed to the low number of water buffaloes sampled due to the coincidence of stool collection period with the harvesting season in the study area. Sample turnout could be further improved by scheduling the collection on days where more animal owners are available.

In a study conducted in 2012, the FEA-SD technique provided a high sensitivity of $97.62 \%$ and was able to detect both high- and low-intensity 


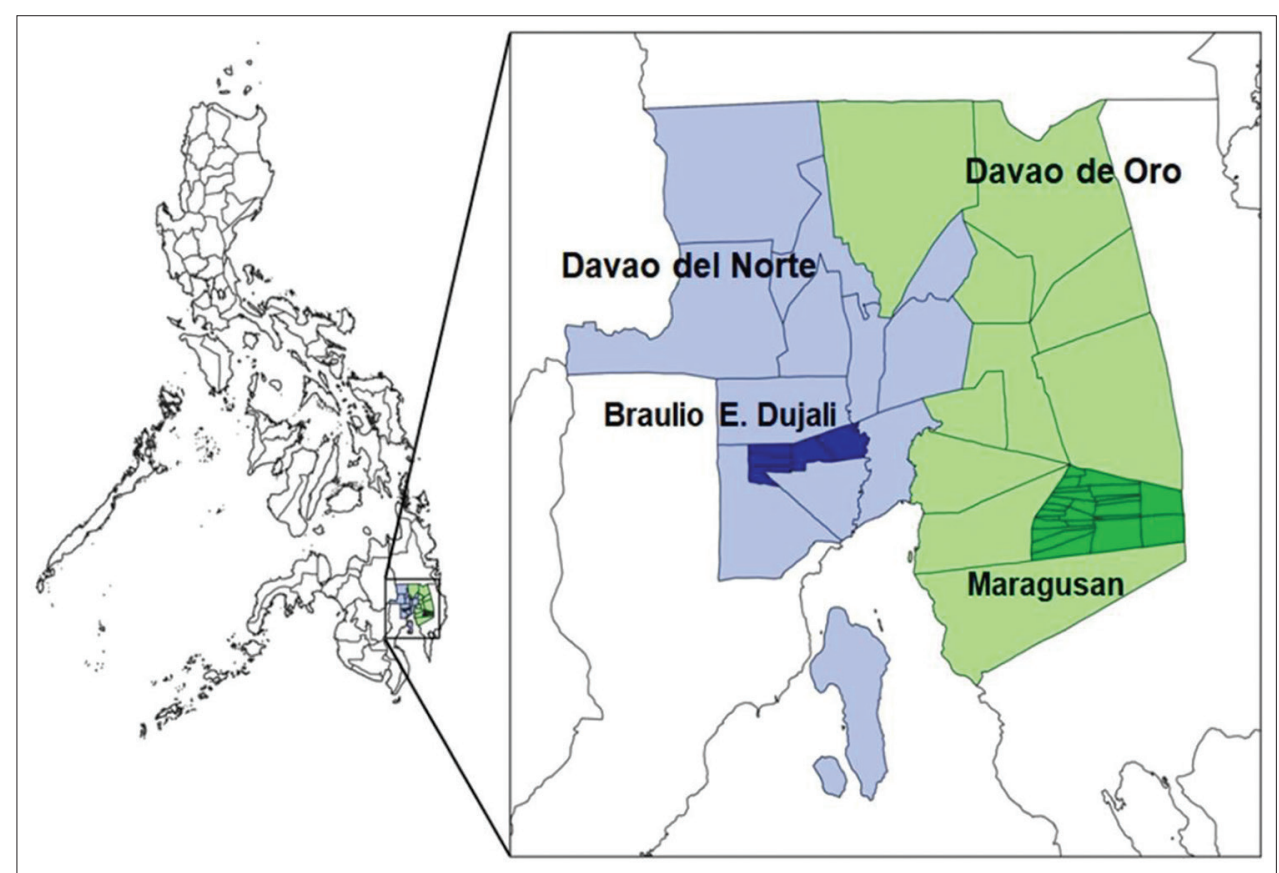

Figure-1: Map of the Philippines (left) and provinces of Davao del Norte and Davao de Oro (right) showing the selected municipalities [Source: Map generated using free and open-source QGIS software version 3.1.6].

Table-1: Prevalence of helminths in water buffaloes by formalin-ethyl acetate sedimentation technique in selected municipalities, Braulio Dujali, Davao del Norte and Maragusan, Davao de Oro, the Philippines, September 2019.

\begin{tabular}{|c|c|c|c|c|c|c|}
\hline \multirow{3}{*}{ Parasite } & \multicolumn{4}{|c|}{ Municipality } & \multirow{2}{*}{\multicolumn{2}{|c|}{$\begin{array}{l}\text { Total } \\
\mathrm{n}=91\end{array}$}} \\
\hline & \multicolumn{2}{|c|}{ Braulio Dujali $(n=56)$} & \multicolumn{2}{|c|}{ Maragusan $(n=35)$} & & \\
\hline & No. & $(\%)$ & No. & $(\%)$ & No. & $(\%)$ \\
\hline Fasciola spp. & 33 & (58.9) & 16 & $(45.7)$ & 49 & $(53.8)$ \\
\hline Paramphistome spp. & 8 & $(14.3)$ & 11 & $(31.4)$ & 19 & (20.9) \\
\hline Amphistome spp. & 10 & $(17.9)$ & 5 & $(14.3)$ & 15 & $(16.5)$ \\
\hline Strongyle spp. & 3 & $(5.4)$ & 7 & $(20.0)$ & 10 & $(11.0)$ \\
\hline Balantidium spp. & 8 & $(14.3)$ & 1 & $(2.9)$ & 9 & $(9.9)$ \\
\hline Schistosoma japonicum & 0 & $(0.0)$ & 3 & $(8.6)$ & 3 & (3.3) \\
\hline Eurytrema spp. & 0 & $(0.0)$ & 2 & $(5.7)$ & 2 & $(2.2)$ \\
\hline Gongylonema pulchrum & 0 & $(0.0)$ & 1 & $(2.9)$ & 1 & $(1.1)$ \\
\hline
\end{tabular}

infections [16]. However, in 2015, FEA-SD was observed to have moderate sensitivity $(60.8 \%)$ and low specificity $(32.1 \%)$ with qPCR as a reference standard, which may have been due to lower fecal volume read [12]. The lower intensity of infection is harder to detect using less sensitive techniques [16]. Possible low-intensity infections could have been missed by the technique, which contributed to the low overall prevalence. This result can be improved by adjusting the FEA-SD protocol [16] so that all sediments after digestion are examined. Moreover, the use of a more sensitive technique (e.g., validated quantitative real-time PCR [qPCR] alone or in combination with FEA-SD) can provide a more accurate estimate of infections [12].

However, the low prevalence in water buffaloes in the Davao Region is similar to the results of the previous studies $[17,18]$, where none or only a small proportion of water buffaloes were positive in an SCH-endemic region. In addition, water buffaloes tend to self-cure; thus, the time period they excrete eggs in their feces is short [19]. This result suggests that even in endemic regions, infection in water buffaloes may vary. Surveillance among other mammalian hosts may be required to further understand the role of animals in the transmission of SCH in the region. The presence of snail intermediate host is also important in disease transmission. A previous study identified snail colonies in barangays in some municipalities in DDN [20] and DDO [21]. However, these snails may not harbor infectious cercariae at the time of collection, which may also contribute to the low prevalence of $S$. japonicum in water buffalo at one study site.

Despite the low prevalence observed, the presence of $S$. japonicum among water buffaloes can contribute to transmission and reinfection in both humans and water buffaloes, as determined in other studies [7,22]. DDN and DDO remain listed as provinces with high prevalence of SCH in humans [23]; thus, the role of water buffaloes needs to be fully established. Bovines, which act as reservoir hosts, may deposit their feces in water bodies near villages where humans 


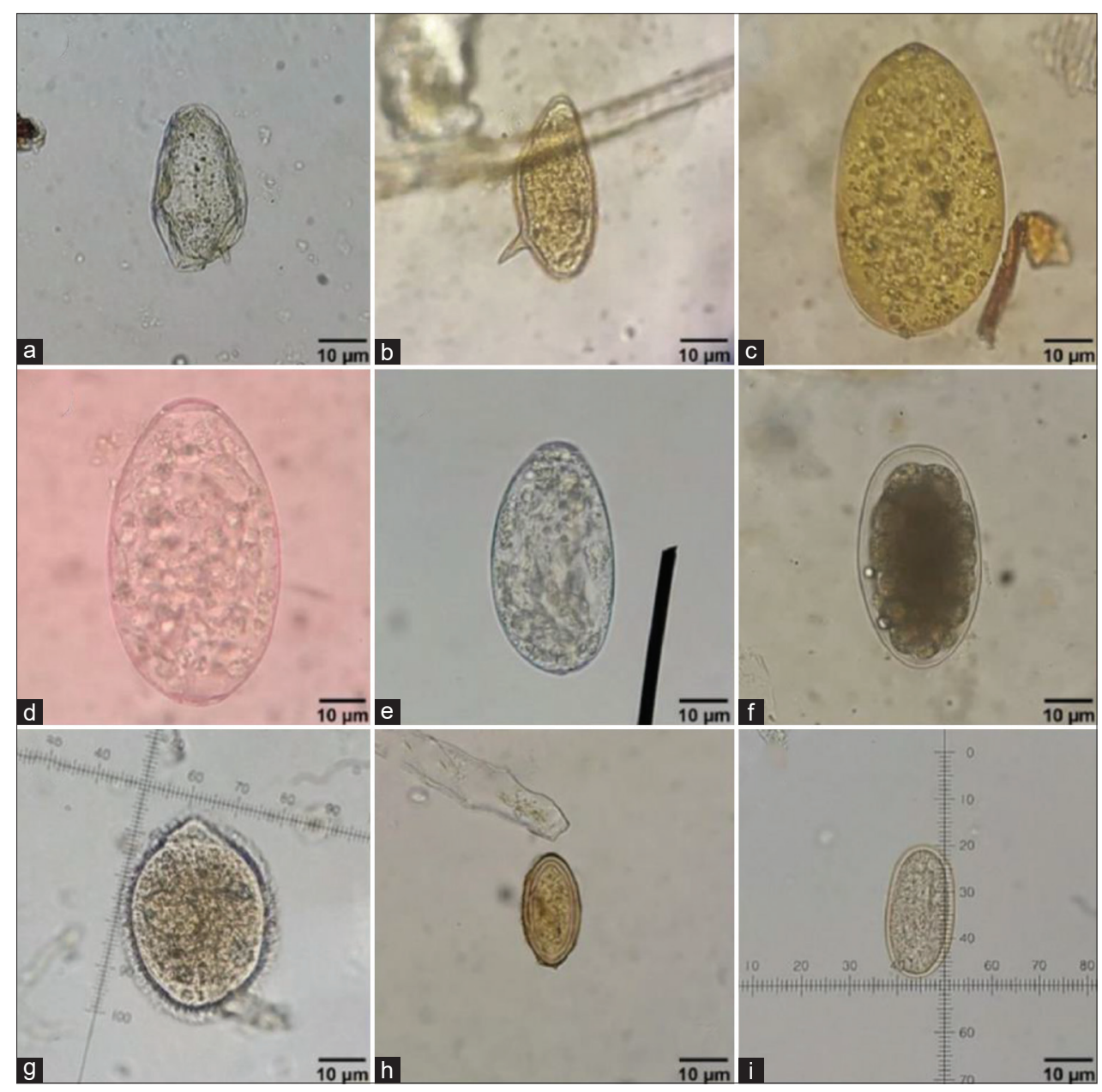

Figure-2: Parasite ova identified from water buffalo feces using formalin-ethyl acetate sedimentation technique. (a) S. japonicum. (b) Schistosoma spp. with long spine (in cow). (c) Fasciola spp. (d) Paramphistome spp. (e) Amphistome spp. (f) Strongyle spp. (g) Balantidium spp. (h) Eurytrema spp. (i) Gongylonema pulchrum (scale bar = $10 \mu \mathrm{m}$ ).

reside and go about their daily activities, which make cross-transmission inevitable [7]. The use of bovine feces as fertilizers in agricultural settings is another important factor in sustaining the disease cycle [24]. These conditions increase the risk factor of SCH zoonotic transmission and are most visible in areas (such as the study sites) where agriculture is the main source of livelihood, which compels farmers to rely on and live in proximity with water buffaloes. In addition, local villages tend to transport water buffaloes from $\mathrm{SCH}-$-endemic areas to non-endemic areas, which may facilitate the transmission of $\mathrm{SCH}$. Comingling of water buffaloes with other livestock animals may also facilitate disease transmission [25]. Furthermore, the study provides baseline data on the infection in water buffaloes in Davao Region, Mindanao. Because the previous studies conducted in the country were limited to some areas in Luzon [10], Visayas [11,12,16], and South Cotabato, Mindanao [13].

A total of one stool sample obtained from a cow showed Schistosoma spp. ova with a prominent lateral spine (Figure-2b), which is a typical characteristic of $S$. mansoni. However, no cases of $S$. mansoni infection have been reported in the Philippines. $S$. mansoni is only reported in humans, monkeys, and rodents [26,27], while bovines are known to be naturally infected [28]. This incidental result warrants an additional confirmation technique, such as PCR, to speciate and confirm identification.

Fasciola spp. was the most prevalent parasite $(53.8 \%)$ observed in the sampled water buffaloes. A study conducted in North Samar also revealed the high prevalence of Fasciola gigantica in water buffaloes at $95.2 \%$ and $96.2 \%$ by FEA-SD and qPCR techniques, respectively. Furthermore, 56 water buffaloes were observed to be coinfected with both $S$. japonicum and F. gigantica [12]. The high prevalence of Fasciola spp. has been observed in water buffaloes and is considered pathologic [29]. Two species, F. gigantica and Fasciola hepatica, are both important parasitic diseases affecting livestock and are known to cause human fasciolosis. Fasciolosis in humans has been reported in Asian countries such as Vietnam [30], Korea [31], and Nepal [32], but not in the Philippines. These findings raised public health importance and the need to survey both humans and animals in areas with high prevalence to investigate potential human infection. Molecular targets have been developed to speciate Fasciola spp. [33] and maybe useful tools to detect infection. 
Other helminths were also observed in fecal samples despite the biannual deworming of water buffaloes. The current treatment regimen being used in DDN and DDO must be reviewed because albendazole, the drug of choice in the communities, is only effective against adult flukes [34]. A previous study in the Philippines also showed evidence of resistance of Fasciola spp. to albendazole, triclabendazole, and bromofenofos in water buffaloes [35]. This warrants another study to investigate anthelmintic susceptibility in bovines.

Effective prevention and control of SCH entails not only human but also animal and environmental health. SCH identified in the water buffaloes at the study sites can be used to support a One Health approach [3] and gather support from animal and health agencies, as well as other sectors toward control and elimination of SCH in the Philippines. Active surveillance and the use of appropriate techniques will aid in the accurate diagnosis of infection in animals. With the established presence of Schistosoma spp. among water buffaloes, strategies toward control and elimination of $\mathrm{SCH}$ in animal reservoir hosts are necessary for the long-term control and elimination of $\mathrm{SCH}$ in humans [36,37].

Treatment of water buffaloes with other drugs (e.g., praziquantel), as done in China [20], can be explored in the Philippines. Praziquantel has been determined to be $97 \%$ effective for $\mathrm{SCH}$ in water buffaloes without major side effects [20]. The data produced by this study can be used as a basis for the Department of Health (DOH) in including animal SCH in their control program. The DOH and Department of Agriculture are just beginning to strategize intervention measures to address the presence of animal reservoirs that facilitate transmission to humans [3]. Innovative approaches, such as shifting to mechanized farming, have also been shown to be effective [38]. Collaboration between these agencies is critical for coordinated efforts to cut the transmission of SCH through animals. The capacity building of regional animal disease diagnostic laboratories and local veterinarians is also needed to support the farmers in disease diagnosis and accurate reporting and to support disease control programs in the health sector.

\section{Conclusion}

This study provides baseline data on the presence of $S$. japonicum in water buffaloes in selected barangays in the Davao Region, Mindanao, using the FEA-SD technique. Active surveillance in animals is necessary to estimate the disease's burden in animals and understand the role of water buffaloes in the transmission of S. japonicum in humans in the Philippines. Early detection and treatment in animals will prevent contamination of the environment and infection in humans.

\section{Authors' Contributions}

RCN, AED, and VYB contributed to the conceptualization and design of the research. RCN, AED, and JMF performed literature search, data acquisition, data analysis, manuscript preparation, manuscript editing, and manuscript review. LADO performed literature search, data analysis, manuscript preparation, manuscript editing, and manuscript review. VYB helped in the manuscript preparation, editing, and review. All authors have read and approved the final manuscript.

\section{Acknowledgments}

The authors would like to thank the Commission on Higher Education of the Philippines through their Discovery-Applied Research and Extension of Trans/ Interdisciplinary Opportunity (DARE TO) Grant (Grant Number: DARETO 01-014) for supporting this project. We would like to thank Dr. Rovina Sumabal and Dr. Wilfredo Lindong, Jr. of the Provincial Veterinary Office of Davao del Norte and Davao de Oro; Mr. Roel Nickelson Solano, Mr. Daniel Joeriz De Guzman, Mr. Allen Alonte, and Ms. Jana Lacuna for assisting the research team in collecting water buffalo stools. We would also like to thank Dr. Daphne Vance Lapuag and Dr. Mylene Cabilogan for their assistance in sample processing as well as Dr. Remil Galay and Dr. Billy Divina for their assistance in verifying the parasite identifications.

\section{Competing Interests}

The authors declare that they have no competing interests.

\section{Publisher's Note}

Veterinary World (Publisher of International Journal of One Health) remains neutral with regard to jurisdictional claims in published map and institutional affiliation.

\section{References}

1. World Health Organization. (2020) Schistosomiasis. World Health Organization, Geneva. Available from: https://www. who.int/news-room/fact-sheets/detail/schistosomiasis. Retrieved on 09-05-2020.

2. World Health Organization. (1995) The Control of Schistosomiasis: Second Report of the WHO Expert Committee. World Health Organization, Geneva, Switzerland.

3. Department of Health. (2018) Schistosomiasis Control Program. Available from: https://www.doh.gov.ph/schistosomiasis-control-program. Retrieved on 09-05-2020.

4. Pesigan, T.P., Hairston, N.G., Jauregui, J.J., Garcia, E.G., Santos, A.T., Santos, B.C. and Besa, A.A. (1958) Studies on Schistosoma japonicum infection in the Philippines. 2. The molluscan host. Bull. World Health Organ., 18(4): 481-578.

5. Chen, G. (1993) Schistosoma japonicum and S. japonicum-like infections: Epidemiology, clinical and pathological aspects. In: Jordan, P., Webbe, G. and Sturrock, R.F., editors. Human schistosomiasis. CAB International, Wallingford. p237-270.

6. He, Y., Salafsky, B. and Ramaswamy, K. (2001) Hostparasite relationships of Schistosoma japonicum in mammalian hosts. Trends Parasitol., 17(7): 320-324. 
7. Ross, A.G.P., Sleigh, A.C., Li, Y., Davis, G.M., Williams, G.M., Jiang, Z., Feng, Z. and McManus, D.P. (2001) Schistosomiasis in the people's republic of China: Prospects and challenges for the $21^{\text {st }}$ century. Clin. Microbiol. Rev., 14(2): 270-295.

8. Gray, D.J., Williams, G.M., Li, Y., Chen, H., Li, R.S., Forsyth, S.J., Barnett, A.G., Guo, J., Feng, Z. and McManus, D.P. (2007) A cluster-randomized bovine intervention trial against Schistosoma japonicum in the people's republic of China: Design and baseline. Am. J. Trop. Med. Hyg., 77(5): 866-874.

9. World Health Organization. (2010) Working to Overcome the Global Impact of Neglected Tropical Diseases: First WHO Report on Neglected Tropical Diseases. World Health Organization, Geneva, Switzerland.

10. Angeles, J.M.M., Goto, Y., Kirinoki, M., Asada, M., Leonardo, L.R., Rivera, P.T., Villacorte, E.A., Inoue, N., Chigusa, Y. and Kawazu, S.I. (2012) Utilization of ELISA using thioredoxin peroxidase-1 and tandem repeat proteins for diagnosis of Schistosoma japonicum infection among water buffaloes. PLoS Negl. Trop. Dis., 6(8): e1800.

11. Wu, H.W., Qin, Y.F., Chu, K., Meng, R., Liu, Y., McGarvey, S.T., Olveda, R., Acosta, L., Ji, M.F., Fernandez, T., Friedman, J.F. and Kurtis, J.D. (2010) High prevalence of Schistosoma japonicum infection in water buffaloes in the Philippines assessed by real-time polymerase chain reaction. Am. J. Trop. Med. Hyg., 82(4): 646-652.

12. Gordon, C.A., Acosta, L.P., Gobert, G.N., Jiz, M., Olveda, R.M., Ross, A.G., Gray, D.J., Williams, G.M., Harn, D., Li, Y. and McManus, D.P. (2015) High prevalence of Schistosoma japonicum and Fasciola gigantica in bovines from Northern Samar, the Philippines. PLoS Negl. Trop. Dis., 9(2): e0003108.

13. Tenorio, J.C. and Molina, E.C. (2020) Schistosoma japonicum infections in cattle and water buffaloes of farming communities of Koronadal City, Philippines. Int. J. One Health, 6(1): 28-33.

14. Philippine Statistics Authority. (2015) Davao Region. Available from: https://www.psa.gov.ph/classification/psgc/?q=psgc/provinces $/ 110000000$. Retrieved on 01-06-2020.

15. Xu, B., Gordon, C.A., Hu, W., McManus, D.P., Chen, H., Gray, D., Ju, C., Zeng, X.J., Gobert, G.N., Ge, J., Lan, W.M., Xie, S.Y., Jiang, W.S., Ross, A.G., Acosta, L.P., Olveda, R. and Feng, Z. (2012) A novel procedure for precise quantification of Schistosoma japonicum eggs in bovine feces. PLoS Negl. Trop. Dis., 6(12): e1885.

16. Gordon, C.A., Acosta, L.P., Gray, D.J., Olveda, R.M., Jarilla, B., Gobert, G.N., Ross, A.G. and McManus, D.P. (2012) High prevalence of Schistosoma japonicum infection in carabao from Samar Province, the Philippines: Implications for transmission and control. PLoS Negl. Trop. Dis., 6(9): e1778.

17. Matsumoto, J., Kirinoki, M., Kawai, S., Chigusa, Y., Ilagan, E.J., Ducusin, B.E., Yasuraoka, K. and Matsuda, H. (1999) Prevalence of Schistosomiasis japonica among school children and animal reservoirs in Oriental Mindoro, Philippines. Jpn. J. Trop. Med. Hyg., 27(2): 175-180.

18. Fernandez, T.J., Tarafder, M.R., Balolong, E. Jr., Joseph, L., Willingham, A.L., Bélisle, P., Webster, J.P., Olveda, R.M., McGarvey, S.T. and Carabin, H. (2007) Prevalence of Schistosoma japonicum infection among animals in fifty villages of Samar Province, The Philippines. Vector Borne Zoonotic Dis., 7(2): 147-155.

19. Li, Y.S., McManus, D.P., Lin, D.D., Williams, G.M., Harn, D.A., Ross, A.G., Feng, Z. and Gray, D.J. (2014) The Schistosoma japonicum self-cure phenomenon in water buffaloes: Potential impact on the control and elimination of schistosomiasis in China. Int. J. Parasitol., 44(3-4): 167-171.

20. Belizario, V.Y., delos Trinos, J.P.C., Silawan, B., de
Veyra, C.M., Hornido, A., Amoguis, H., Basalo, D., Dema-Ala, C., Mantilla, I. and Layan, R. (2017) The use of geographic information system as a tool for schistosomiasis surveillance in the Province of Davao Del Norte, The Philippines. Geospat. Health., 12(2): 540.

21. Fornillos, R., Sato, M.O., Tabios, I., Sato, M., Leonardo, L.R., Chigusa, Y., Minamoto, T., Kikuchi, M., Legaspi, E.R. and Fontanilla, I.K.C. (2019) Detection of Schistosoma japonicum and Oncomelania hupensis quadrasi environmental DNA and its potential utility to schistosomiasis japonica surveillance in the Philippines. PLoS One, 14(11): e0224617.

22. Wang, T., Zhang, S., Wu, W., Zhang, G., Lu, D., Ørnbjerg, N. and Johansen, M.V. (2006) Treatment and reinfection of water buffaloes and cattle infected with Schistosoma japonicum in Yangtze River Valley, Anhui province, China. $J$. Parasitol., 92(5): 1088-1091.

23. Leonardo, L., Rivera, P., Saniel, O., Villacorte, E., Lebanan, M.A., Crisostomo, B., Hernandez, L., Baquilod, M., Erce, E., Martinez, R. and Velayudhan, R. (2012) A national baseline prevalence survey of schistosomiasis in the Philippines using stratified two-step systematic cluster sampling design. J. Trop. Med., 2012: 936128.

24. Spear, R.C., Seto, E., Liang, S., Birkner, M., Hubbard, A., Qiu, D., Yang, C., Zhong, B., Xu, F., Gu, X. and Davis, G.M. (2004) Factors influencing the transmission of Schistosoma japonicum in the mountains of Sichuan Province of China. Am. J. Trop. Med. Hyg., 70(1): 48-56.

25. Villanueva, M.A., Mingala, C.N., Tubalinal, G.A.S., Gaban, P.B.V., Nakajima, C. and Suzuki, Y. (2018) Emerging infectious diseases in water buffalo: An economic and public health concern. In: Emerging Infectious Diseases in Water Buffalo an Economic and Public Health Concern. Intech Open, London.

26. Catalano, S., Sène, M., Diouf, N.D., Fall, C.B., Borlase, A., Léger, A., Bâ, K. and Webster, J.P. (2018) Rodents as natural hosts of zoonotic Schistosoma species and hybrids: An epidemiological and evolutionary perspective from West Africa. J. Infect. Dis., 218(3): 429-433.

27. Catalano, S., Léger, E., Fall, C.B., Borlase, A., Diop, S.D., Berger, D., Webster, B.L., Faye, B., Diouf, N.D., Rollinson, D., Sène, M., Bâ, K. and Webster, J.P. (2020) Multihost transmission of Schistosoma mansoni in Senegal, 2015-2018. Emerg. Infect. Dis., 26(6): 1234-1242.

28. Barbosa, F.S., Barbosa, I. and Arruda, F. (1962) Schistosoma mansoni: Natural infection of cattle in Brazil. Science, 138(3542): 831.

29. Molina, E.C., Gonzaga, E.A. and Lumbao, L.A. (2005) Prevalence of infection with Fasciola gigantica and its relationship to carcass and liver weights, and fluke and egg counts in slaughter cattle and buffaloes in southern Mindanao, Philippines. Trop. Anim. Health Prod., 37(3): 215-221

30. Le, T.H., De, N.V., Agatsuma, T., Nguyen, T.G.T., Nguyen, Q.D., McManus, D.P. and Blair, D. (2008) Human fascioliasis and the presence of hybrid/introgressed forms of Fasciola hepatica and Fasciola gigantica in Vietnam. Int. J. Parasitol., 38(6): 725-730.

31. Kim, A.J., Choi, C.H., Choi, S.K., Shin, Y.W., Park, Y.K., Lucia, K., Choi, S.J., Han, J.Y., Kim, J.M., Chu, Y.C. and Park, I.S. (2015) Ectopic human Fasciola hepatica infection by an adult worm in the Mesocolon. Korean J. Parasitol., 53(6): 725-730.

32. Sah, R., Khadka, S., Khadka, M., Gurubacharya, D., Sherchand, J.B., Parajuli, K., Shah, N.P., Kattel, H.P., Pokharel, B.M. and Rijal, B. (2017) Human fascioliasis by Fasciola hepatica: The first case report in Nepal. BMC Res. Notes, 10(1): 439.

33. Huang, W.Y., He, B., Wang, C.R. and Zhu, X.Q. (2004) Characterisation of Fasciola species from mainland China by ITS-2 ribosomal DNA sequence. Vet. Parasitol., 120(1-2): 75-83. 
34. Alvarez, L., Moreno, G., Moreno, L., Ceballos, L., Shaw, L., Fairweather, I. and Lanusse, C. (2009) Comparative assessment of albendazole and triclabendazole ovicidal activity on Fasciola hepatica eggs. Vet. Parasitol., 164(2-4): 211-216.

35. Venturina, V.M., Alejandro, M.A.F., Baltazar, C.P., Abes, N.S. and Mingala, C.N. (2015) Evidence of Fasciola spp. resistance to albendazole, triclabendazole and bromofenofos in water buffaloes (Bubalus bubalis). Ann. Parasitol., 61(4): 283-289.

36. Wang, T.P., Ge, J.H., Wu, W.D., Zhang, S.Q., Lu, D.B., Zhang, G.H. (1997) Infection sources of schistosomiasis and their role in the transmission in lake and marshland regions in Anhui province. Chin. J. Parasit. Dis. Control,
11(3): $138-141$

37. Wang, T.P., Maria, V.J., Zhang, S.Q., Wang, F.F., Wu, W.D., Zhang, G.H., Pan, X.P., Ju, Y. and Ørnbjerg, N. (2005) Transmission of Schistosoma japonicum by humans and domestic animals in the Yangtze River valley, Anhui province, China. Acta Trop., 96(2-3): 198-204.

38. Wang, L.D., Guo, J.G., Wu, X.H., Chen, H.G., Wang, T.P., Zhu, S.P., Zhang, Z.H., Steinmann, P., Yang, G.J., Wang, S.P., Wu, Z.D., Wang, L.Y., Hao, Y., Bergquist, R., Utzinger, J. and Zhou, X.N. (2009) China's new strategy to block Schistosoma japonicum transmission: Experiences and impact beyond schistosomiasis. Trop. Med. Int. Health, 14(12): 1475-1483.

$* * * * * * * *$ 